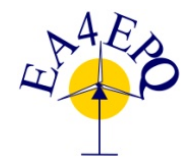

International Conference on Renewable Energies and Power Quality (ICREPQ'13)

Bilbao (Spain), $20^{\text {th }}$ to $22^{\text {th }}$ March, 2013

Renewable Energy and Pourer Qualily. Fournal (RE\&PQJ)

ISSN 2172-038 X, No.11, March 2013

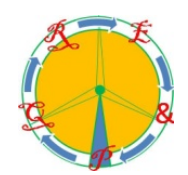

\title{
Influence of flux estimation in performance of direct torque control of PMSM
}

\author{
P. Fernández ${ }^{1}$ J. A. Güemes ${ }^{2}$, and A. Iraolagoitia ${ }^{2}$ \\ ${ }^{1}$ Department of Electronics Technology, ${ }^{2}$ Department of Electrical Engineering \\ University of the Basque Country (EUITI) \\ Paseo Rafael Moreno "Pichichi", 348013 Bilbao (Spain) \\ e-mail: pablo.fernandezr@ehu.es, joseantonio.guemes@ehu.es, ana.iraolagoitia@ehu.es
}

\begin{abstract}
Permanent magnet synchronous motors (PMSMs) are extensively used in high-performance industrial applications. High dynamic response can be achieved by means of direct torque control (DTC). The main advantage of DTC is that coordinate transformations and pulse width modulation (PWM) generation are not needed, however, classical DTC produces high torque ripple. This paper presents a comparison of different flux estimation methods to implement DTC drive systems, and shows the influence of the choice of estimation method on torque ripple.
\end{abstract}

\section{Key words}

Motor drives, permanent magnet motors, torque control.

\section{Introduction}

Research works on DTC applied to induction motors [1][2] appeared in the 1980's, introducing an alternative to vector control requiring no axis transformations to the rotor-fixed coordinate system and with less dependence on machine parameters.

Since then, several research works have shown the possibilities of applying DTC to PMSMs [3]-[4], as attention to its higher power density and efficiency rates grew strong with the appearance of $\mathrm{NdFeB}$ magnets. Their high coercivity values and extended lifetime made it possible for the PMSMs to reach application fields that up to then were reserved for the induction motors.

Use of DTC for PMSMs makes possible the implementation of sensorless speed drives [5]-[6], with the consequent reduction of manufacturing costs and higher robustness. Torque and flux are estimated from actual values of stator current and voltage, and two hysteresis controllers compare estimation with reference torque and flux values. The hysteresis signals control a voltage-source inverter which feeds stator windings with the required voltage vector in order to maintain torque and flux values under control.
An important disadvantage of this scheme is that PMSM drive performance is severely influenced by the accuracy of stator flux-linkage vector. Estimation of stator fluxlinkage vector is critical as it determines rotor position, which is needed to select appropriate voltage vector; and also it is part of estimation of developed torque, used to determine error signal of control system.

In recent research works [7]-[9], many authors have given attention to improve accuracy of stator flux-linkage vector estimation, with different proposals, based on voltage vector components in the stator coordinate system.

We will consider the following:

1) open-loop integrator;

2) open-loop low-pass filter;

3) closed-loop integrator with PI.

The objective of this paper is to perform a comparison of different strategies to estimate stator flux-linkage vector, and also to investigate its influence on developed torque ripple of a DTC applied to a PMSM. A sensorless speed control for a PMSM was also simulated to compare performances of different estimation methods.

\section{Motor model}

We use as motor model equations in the stator coordinate system D-Q axis. For this coordinate system, equations describing electrical and mechanical magnitudes of a PMSM are:

$$
\begin{gathered}
u_{D}=R_{s} i_{D}+\frac{\partial \psi_{D}}{\partial t} ; \psi_{D}=L_{D} i_{D}+\psi_{m D} \\
u_{Q}=R_{s} i_{Q}+\frac{\partial \psi_{Q}}{\partial t} ; \psi_{Q}=L_{Q} i_{Q}+\psi_{m Q} \\
T=\frac{3 p}{2}\left(\psi_{D} i_{Q}-\psi_{Q} i_{Q}\right)
\end{gathered}
$$




$$
\frac{d^{2} \theta}{d t^{2}}=\left(T-T_{l}-B \frac{d \theta}{d t}\right) \frac{1}{J} ; \omega=\frac{d \theta}{d t}
$$

where $u_{D}, u_{Q}, i_{D}$ and $i_{Q}$ are the stator voltage and current components in the $D-Q$ axis coordinate system, $R_{s}$ is the stator resistance, $L_{D}$ and $L_{Q}$ are inductance values, $\psi_{D}$ and $\psi_{Q}$ are the $D-Q$ axis components of stator flux, $\psi_{m D}$ and $\psi_{m Q}$ are the rotor magnet flux components, $p$ is the pole pair number, $\omega$ is rotor speed, $\theta$ is rotor angle, $J$ is rotor mass moment of inertia, $B$ is a constant related to friction and $T$ and $T_{l}$ are electromagnetic and load torque.

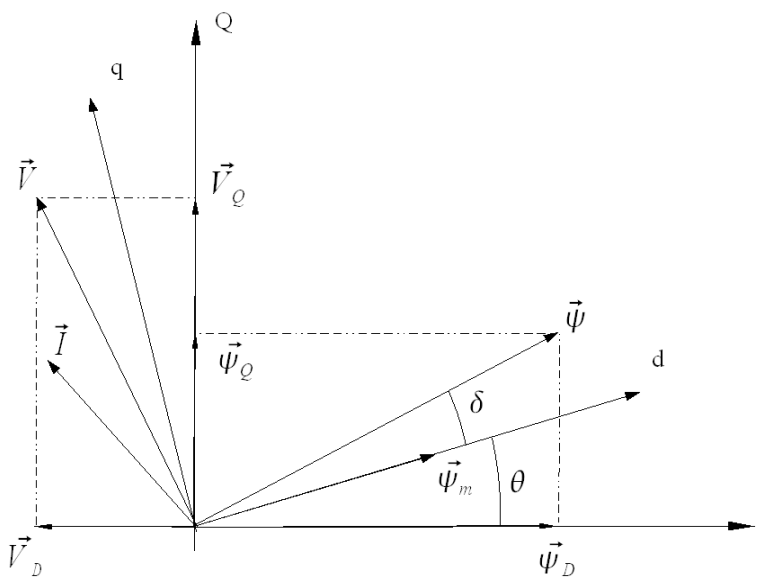

Fig. 1. Vector diagram of the PMSM in stator coordinates.

Figure 1 shows vector diagram representing a PMSM. In this diagram, in addition to stator coordinate $D-Q$ system, $d-q$ coordinate system moving with the rotor is included. As $d$-axis is aligned with magnet flux axis, and $d$-q coordinate system moves jointly with rotor poles, magnet flux-linkage vector orientation always represents rotor angle $\theta$. As long as we can calculate torque angle $\delta$ (angle between stator flux and rotor flux vectors), is possible to obtain rotor angle from stator flux vector angle, given by its two components $\psi_{D}$ and $\psi_{Q}$.

\section{Basic DTC concept}

Motor torque developed by a PMSM is also given by:

$$
T=\frac{3 p \psi}{4 L_{d} L_{q}}\left(2 \psi_{m} L_{q} \sin \delta+\psi\left(L_{d}-L_{q}\right) \sin 2 \delta\right)
$$

where $\psi_{\mathrm{m}}$ is the rotor flux, $L_{d}$ and $L_{q}$ are stator winding inductances in rotor-fixed direct and quadrature axis, $\psi$ is the stator flux and $\delta$ is the torque angle.

It can be seen from equation (5) that developed torque is directly proportional to torque angle, when flux is constant. So, we can control torque by increasing or decreasing angle $\delta$. This expression allows us also to calculate torque angle for a given torque and stator flux values.

In PMSMs, stator flux vector can be described by:

$$
\vec{\psi}=\int\left(\vec{V}_{s}-R_{s} \vec{I}\right) d t
$$

where $v_{s}$ and $i_{s}$ are stator voltage and current vectors.
During the integration interval, we can assume that voltage vector is constant, so:

$$
\vec{\psi}\left(t_{1}\right)=\vec{V}_{s} \Delta t-R_{s} \int \vec{I} d t+\vec{\psi}\left(t_{0}\right)
$$

Neglecting stator resistance voltage drop, equation (7) shows that stator flux can be calculated as the sum of stator flux vector and a vector with the same orientation that stator voltage vector.

A common mode of driving a PMSM is by using a threephase inverter. The switches can be controlled to connect to each phase stator winding positive voltage " 1 ", negative voltage " 1 " or disconnect phase winding from DC voltage supply " 0 ". By selecting the appropriate combination of switching states in the three-phase inverter, voltage vector can be generated in a set of 6 different space orientations, as depicted in Fig. 2.
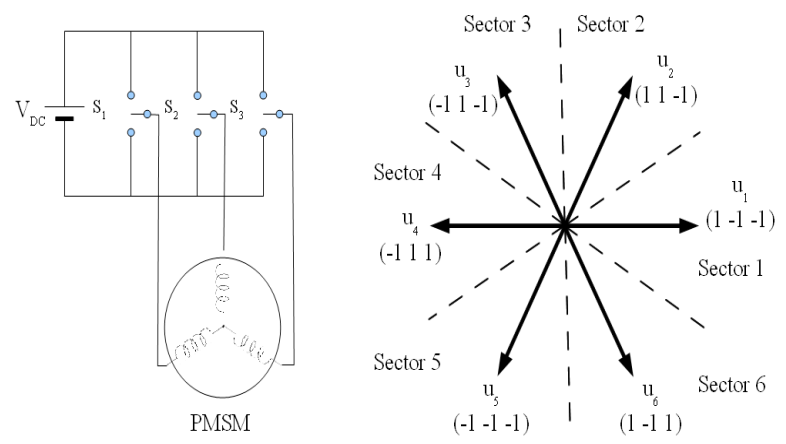

Fig. 2. Three-phase inverter and stator voltage vectors.

The effect of voltage vector on stator flux depends on rotor position, as this determines stator flux vector orientation. As it can be seen on Fig. 3, application of vectors $u_{2}$ and $u_{3}$ results in an increase of torque angle, while voltage vectors $u_{5}$ and $u_{6}$ modify stator flux vector so that torque angle decreases.

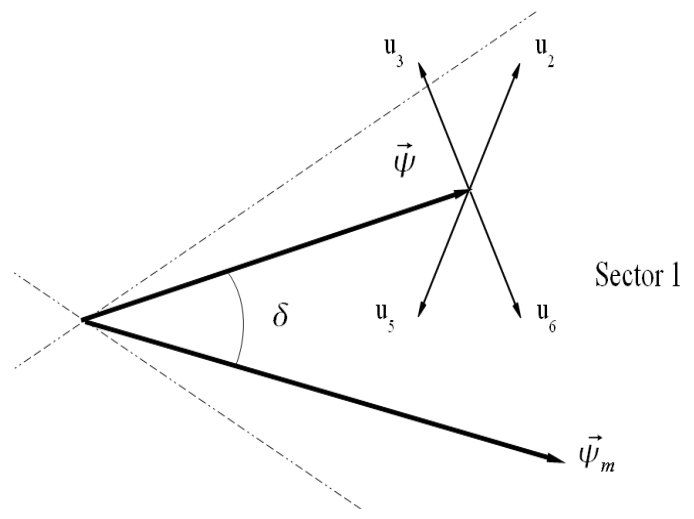

Fig. 3. Effect of voltage vectors on stator flux linkage vector.

The use of voltage vectors to control torque angle gives us an additional chance of controlling motor behavior, as we can also modify stator flux amplitude. In the same figure, it can be seen that voltage vectors $u_{2}$ and $u_{6}$ contribute to higher stator flux amplitude, while vector $u_{3}$ and $u_{5}$ reduce stator flux. 
For the motoring mode and positive rotational speed, stator flux vector leads rotor flux vector, so that an increase in stator flux vector angle increases $\delta$ and developed torque; on the contrary, a reduction of stator flux vector angle decreases $\delta$ and developed torque.

A pair of hysteresis comparators [1], [2] can keep torque and flux amplitude between a given interval, by selecting voltage vector to increase or decrease flux or torque amplitude. To develop this task, accuracy of flux amplitude is of the highest importance to estimate developed torque, as it can be seen in (3). Estimated torque is then compared to reference torque to create error signal for the hysteresis comparators. Table I shows adequate voltage vector selection for control of torque and flux at every rotor position, which is calculated from stator flux angle and torque angle.

TABLE I

Voltage Vector Selection

\begin{tabular}{|c|r|r|r|r|}
\cline { 2 - 5 } \multicolumn{1}{c|}{} & $T \uparrow \psi \uparrow$ & $T \uparrow \psi \downarrow$ & $T \downarrow \psi \uparrow$ & $T \downarrow \psi \downarrow$ \\
\hline $\begin{array}{c}\text { Voltage vector at } \\
n \text { sector }\end{array}$ & $u_{n+1}$ & $u_{n+2}$ & $u_{n-1}$ & $u_{n-2}$ \\
\hline
\end{tabular}

Sampling time of the required voltage vector is most important, as torque variation rate achieved with this method is high. At high sampling times, torque values surpass hysteresis comparator band before switching state has changed to select the appropriate voltage vector. This can lead to high torque ripple.

\section{Stator flux linkage estimation methods}

Estimation of flux-linkage vector can be done directly from equation (6), but some other methods are proposed [7]-[10].

Most of these methods are based on equation (6), as it offers the important advantage of being independent on rotor position and that the only parameter of the machine which needs to be known is the stator resistance $R_{s}$.

However, this value is not a constant, as operation of PMSM involves a change of temperature of stator winding, with the consequent change of stator resistance. At low frequencies, stator voltages are very small and are dominated by ohmic voltage drops. The drive system may become unstable if stator resistance used in the controller differs from real value. Furthermore, errors may occur in the monitored voltages and currents, due to phase shift caused by the sensors or even quantization errors in the digital system.

For these reasons we will compare pure integration of (6) with other flux estimation methods:

\section{A. Open-loop integrator}

Calculation of the stator flux-linkage is done by equation (6). This is an open-loop method and so, there is no chance to correct flux value during operation of drive system:

- any offset in voltage or current measured value may lead to large drift in the estimated flux vector components;

- wrong initialization of integration will add a DC value to its output;

- a different value of $R_{s}$ will cause important errors, especially at low speed.

\section{B. Open-loop low-pass filter}

A low-pass filter (LPF) can overcome the problems of simple integration. Flux estimation is developed by equation (6), but integration is substituted by the following transfer function:

$$
F(s)=\frac{1}{s+\frac{1}{\tau}}
$$

As a LPF is equivalent to a high-pass filter plus an integrator, DC values and dependence on initial values is reduced in the flux estimation.

To obtain a pure integration, the time constant $\tau$ has to be carefully chosen. To obtain good flux estimation at low speeds, time constant should be large, but this will lead to a slow flux estimation.

\section{Closed-loop integrator with PI}

Pure integrator can be used if it is corrected through external feedback. The input of the integrator can be added to an error signal (affected by a PI block), obtained from the comparison of estimated flux-linkage vector and an approximation of the real flux vector. This is calculated using a vector with the magnitude of the flux reference and the same phase than the estimated flux-linkage vector, as depicted in Fig. 4.

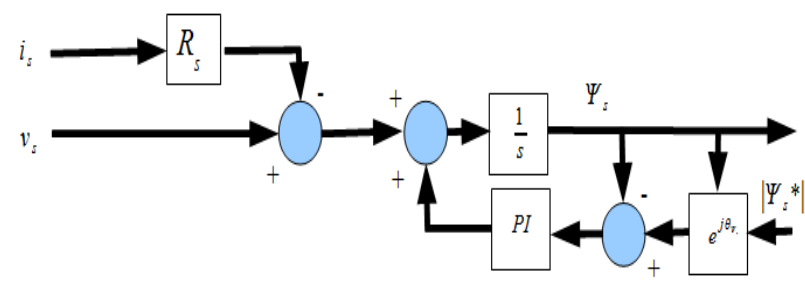

Fig. 4. Closed-loop integrator with PI.

This closed-loop integrator can remove drift problems and correct some of the problems derived from incorrect stator resistance values, but decrease of drive system reaction time and possible phase lags should be taken into consideration.

\section{DTC simulation}

Study of this method was carried out in a numerical simulation of a PMSM, using one of Matlab's toolboxes, 
Simulink. The components of our PMSM and all the components of the DTC system different strategies were simulated using this program's blocks.

For dynamic simulation, equations are written as follows:

$$
\begin{aligned}
& \frac{d \psi_{d}}{d t}=u_{d}-R_{s} i_{d}+\omega \psi_{q} \\
& \frac{d \psi_{q}}{d t}=u_{q}-R_{s} i_{q}+\omega \psi_{d}
\end{aligned}
$$

These equations, with motor torque equation (4) describe electrical and mechanical behavior of PMSM.

We use a model with a $450 \mathrm{~V}$ DC voltage source, feeding a six step three phase inverter for the voltage source connected to the PMSM windings. For this simulation, constant flux reference was selected with the same value than magnet flux-linkage. The complete model for the simulation can be seen on Fig. 5 .

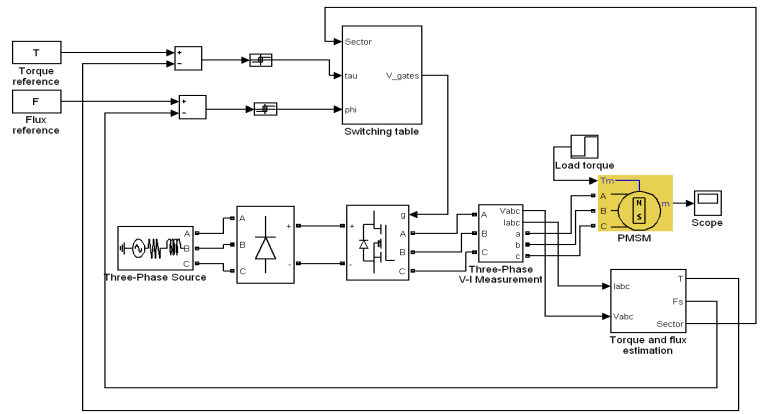

Fig. 5. Model of PMSM and DTC control.

\section{Simulation results}

Simulation of a PMSM with a DTC was performed for different flux-linkage vector estimation strategies.

Fig. 6 shows stator flux-linkage vector represented by its components in the $D-Q$ stator coordinate system. Open loop pure integration was the flux estimation method chosen, and it can be seen that flux vector is centred at the origin, showing no eccentricity in the flux trajectory. Flux estimation method was capable of maintaining flux amplitude within hysteresis comparator limits.

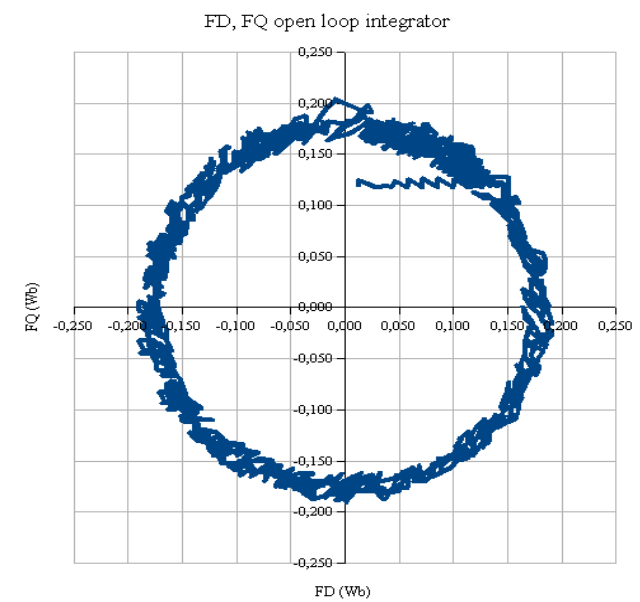

Fig. 6. Stator flux components in the $D-Q$ system.
As it can be seen in Fig. 7, all three methods were able to keep under control stator flux-linkage amplitude, even with a step change of torque reference from $15 \mathrm{Nm}$ to 20 $\mathrm{Nm}$ at $\mathrm{t}=0.1 \mathrm{~s}$.

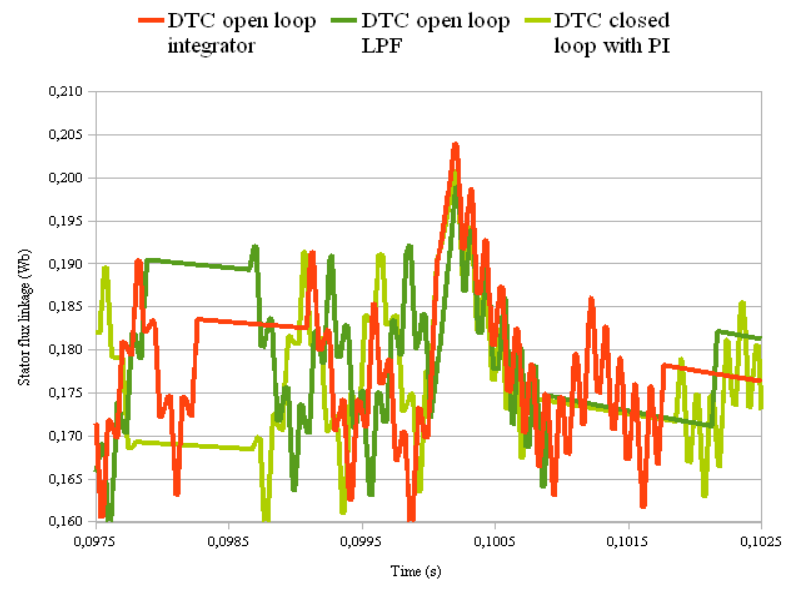

Fig. 7. Stator flux amplitude.

Fig. 8 shows developed torque for all three stator flux -linkage estimation methods. The high dynamic performance of DTC is clear as reference torque is changed at $t=0.1 \mathrm{~s}$ and change of developed torque is achieved in less than $0.5 \mathrm{~ms}$.

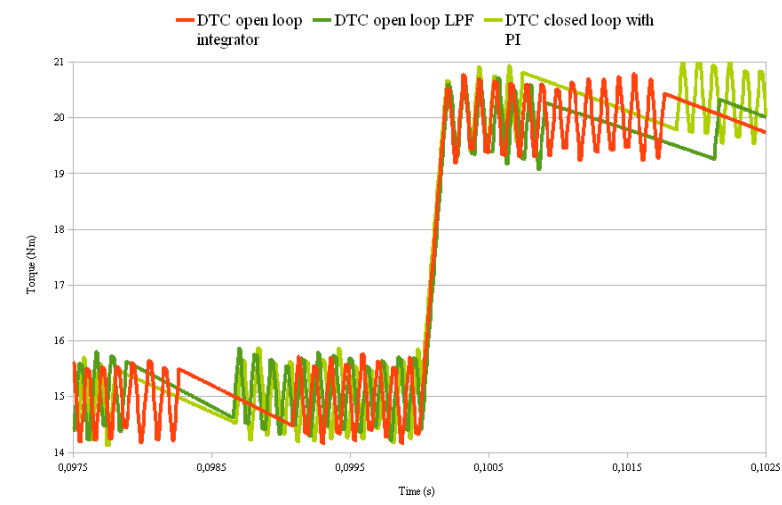

Fig. 8. Torque ripple of DTC.

Torque ripple factor is defined as follows:

$$
t_{r}=\frac{T_{\max }-T_{\min }}{T_{a v}}
$$

For better comparison between flux estimation methods, table II shows maximum, minimum, average torque ( $T_{\max }$, $T_{\min }$ and $T_{a v}$, respectively) and torque ripple factor $\left(t_{r}\right)$ for analyzed DTC control methods.

TABLE II

Torque Values and Ripple Factor for Flux Estimation

\begin{tabular}{|c|c|c|c|c|}
\hline $\begin{array}{c}\text { Flux estimation } \\
\text { method }\end{array}$ & $T_{\max }(\mathrm{Nm})$ & $T_{\min }(\mathrm{Nm})$ & $T_{a v}(\mathrm{Nm})$ & $t_{r}(\%)$ \\
\hline $\begin{array}{c}\text { Open-loop } \\
\text { integration }\end{array}$ & 20.67 & 19.25 & 19.99 & 7.06 \\
\hline Open-loop LPF & 20.64 & 19.01 & 19.81 & 8.20 \\
\hline $\begin{array}{c}\text { Closed-loop } \\
\text { integration }\end{array}$ & 20.68 & 19.32 & 20.05 & 6.77 \\
\hline
\end{tabular}


These results show that:

1) The differences in torque ripple are slight, the three methods are capable of achieving reference torque with accuracy.

2) Flux estimated through open-loop LPF shows a superimposed sinusoidal component, possibly due to phase lag introduced by LPF.

3) The closed-loop integration shows the best results for torque control.

\section{Voltage value error}

Voltage value can be incorrectly estimated for the drive system, due to error in the sensor or signal acquisition phases. A common error that can be easily simulated is an offset value introduced in the flux estimation system as a constant difference between real stator value and values used for integration of stator voltage vector.

An error of $10 \%$ of voltage DC source was used during simulation, with similar results for all three flux estimation methods. As it can be seen in Fig. 9, all three methods were able to keep under control stator fluxlinkage amplitude.

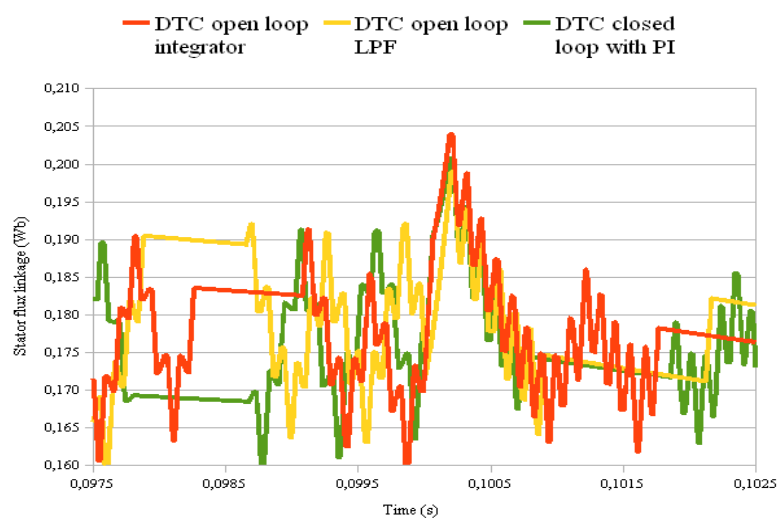

Fig. 9. Stator flux amplitude with voltage error.

As a result, torque value is unaffected (see Fig. 10) by error in stator voltage value, showing no significant difference with that obtained with correct voltage value.

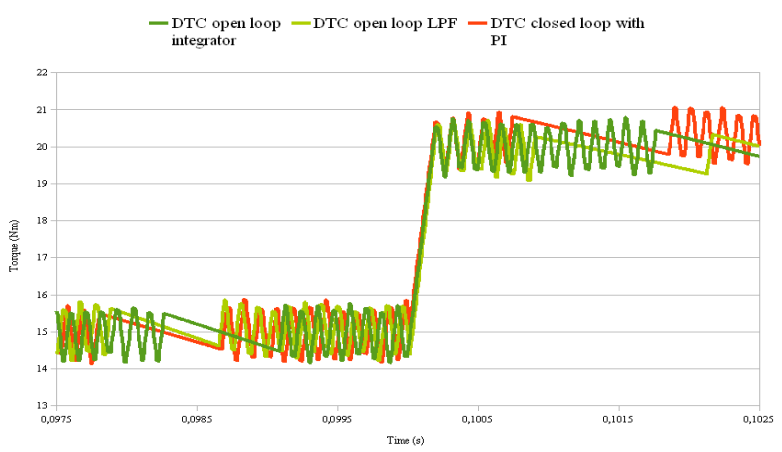

Fig. 10. Torque ripple of DTC with voltage error.

\section{Stator resistance error}

Stator resistance value may change during operation, due to temperature dependence of stator winding resistance.
This will cause an error in the calculation of flux estimated value, with different results depending on estimation method used.

An increase of $10 \%$ on stator resistance value was introduce in the PMSM model, while parameters were left unchanged in the flux estimation systems, simulating a change of stator resistance value during operation of drive system.

Fig. 11 shows stator flux-linkage vector represented by its components in the $D-Q$ stator coordinate system. Compared with Fig. 6, flux vector trajectory shows a difference in flux amplitude repeated four times at every turn of flux vector (as torque angle is kept constant, position of flux vector represent rotor position). The three methods show a very similar performance in this subject, developing rotor position dependence in the stator flux amplitude with slight differences between them.

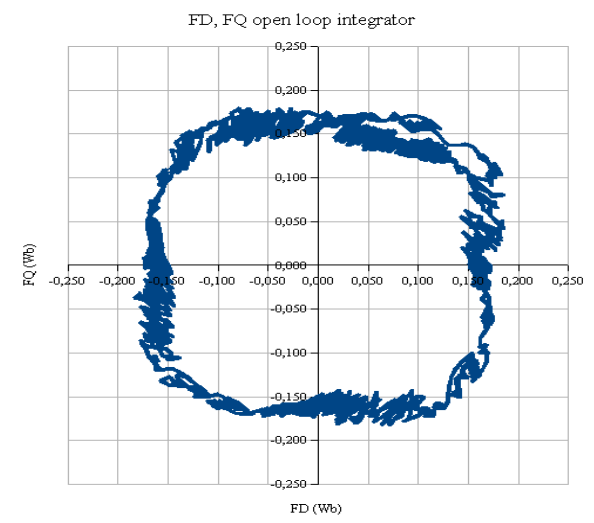

Fig. 11. Stator flux components in the stator coordinate $D-Q$ system with stator resistance error.

Fig. 12 shows that stator flux amplitude during simulation is not significantly different from that obtained without stator resistance error. It is clear, though, that speed of the three different flux estimation systems differ during change of torque reference value, as maximum flux value is achieved at different moments.

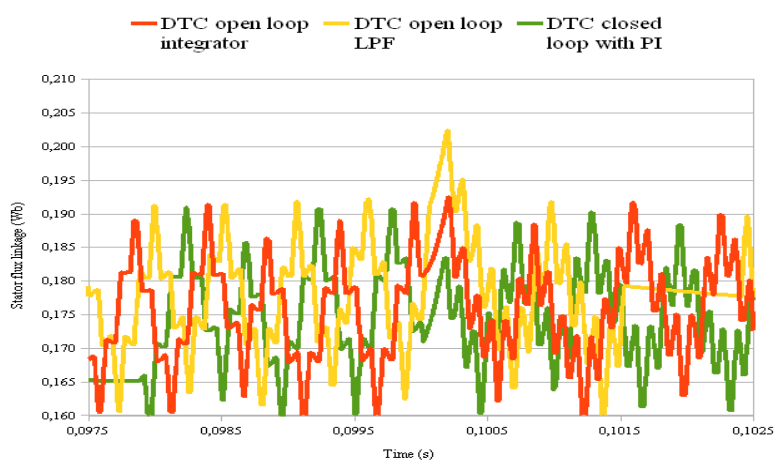

Fig. 12. Stator flux amplitude with resistance error .

The consequences on developed torque are shown at Fig. 13, where a superimposed sinusoidal can be clearly seen added to the reference torque value. Frequency of this sinusoidal increases with time, as expected from information given by Fig. 10. Flux amplitude error is repeated at every rotor turn, and as rotor accelerates, the error is repeated more frequently. 


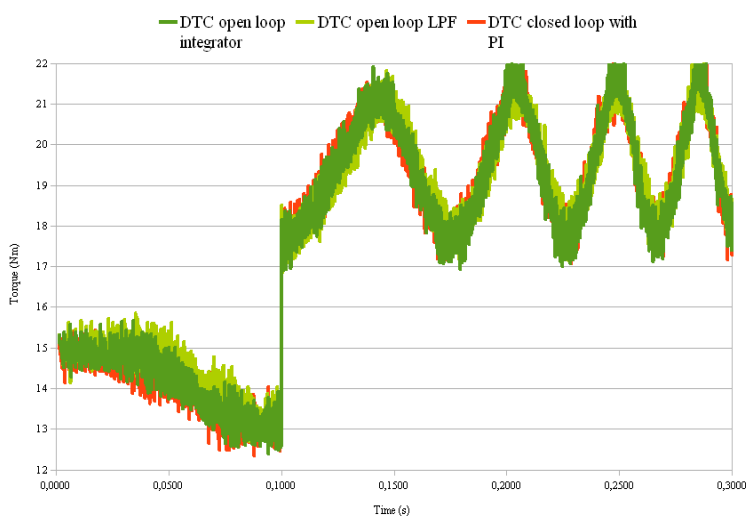

Fig. 13. Developed torque with stator resistance error.

All three methods show a very similar performance in this case, and all reduction on torque ripple is surpassed by effect of stator flux amplitude error caused by change of stator resistance.

\section{Sensorless speed control}

A speed signal can be estimated by differentiation of rotor angular position, obtained from rotor flux vector angle and torque angle in the torque and flux estimation stage. With this speed estimate, a speed control gives a torque and stator flux reference value for the DTC system.

For simulation of sensorless drive, rotor speed is estimated from rotor angle signal with some filtering to reach a smooth signal fit for the speed control. After subtraction from speed reference value, error signal feeds a proportional-integration block that gives torque reference for the DTC control. Flux reference is kept constant during simulation, using magnet flux linkage value for stator flux value.

Fig. 14 shows speed response of PMSM drive during simulation. Load torque was $3 \mathrm{Nm}$ at start, with a step change to $7 \mathrm{Nm}$ at $\mathrm{t}=0.15 \mathrm{~s}$. Control reacts to reach again speed reference value of $150 \mathrm{rpm}$ after such a load increase. Chosen flux estimation method was closed-loop integration.

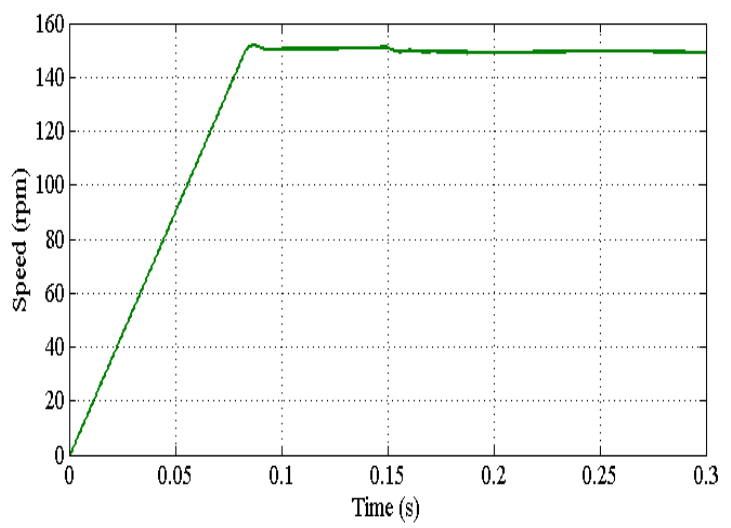

Fig. 14 Rotor speed of PMSM sensorless drive with closed-loop integrator.

\section{Conclusions}

Several simulations of a PMSM controlled by DTC drives were carried out for different flux-linkage estimation methods, and the torque values have been compared.

All three studied methods keep good control on flux reference value, and as a consequence, DTC drive system is capable of maintaining torque reference.

Best results are achieved with closed-loop integration, and torque ripple is reduced in comparison to pure integration for flux-linkage estimation.

Simulation of parameter estimation errors shows that DTC drive is not very sensitive to offset error in voltage value, as no significant difference appears in flux and torque estimation.

Change in stator resistance, on the opposite, affects accuracy of flux estimation and consequently, torque ripple is increased. The three methods show similar results regarding torque ripple.

\section{References}

[1] M. Depenbrock, "Direct self-control of inverter-fed machine," IEEE Trans. Power Electronics, vol. 3, pp. 420-429, Oct. 1988 .

[2] I. Takahashi and T. Naguchi, "A new quick-response and high-efficiency control strategy of an induction motor," IEEE Trans. Industry Applications, vol. IA-22, pp. 820-827, Sept./Oct. 1986.

[3] M. F. Rahman, L. Zhong, and K. W. Lim, "A direct torquecontrolled interior permanent magnet synchronous motor drive," IEEE Trans. On Industry Applications, vol. 34, n 6, pp. 12461253, Nov./Dec.1998.

[4] L. Zhong, M. F. Rahman, W. Y. Hu, and K. W. Lim, "Analysis of direct torque control in permanent magnet synchronous motor drives," IEEE Trans. Power Electronics, vol. 12, pp. 528-536, May 1997.

[5] C. Bian, S. Ren, L. Ma, "Sensorless DTC of super high-speed PMSM," 2007 IEEE Int. Conf. On Automation and Logistics, 2007, pp. 2711-2715.

[6] A. A. Adam, K. Gulez, I. Aliskan, Y. Altun, R. Guclu, M. Metin, "Steering DTC algorithm for IPMSM used in electrical vehicle with fast response and minimum torque ripple," 11th IEEE Int. Workshop on Advanced Motion Control, 2010, pp. 279-283.

[7] P. Vas, Sensorless vector and direct torque control, Oxford University Press, 2003, pp. 124-144.

[8] T.J. Vyncke, R.K Boel and J.A.A. Melkebeek, "On the stator flux linkage estimation of an PMSM with extended Kalman filters," 5th IET International Conference on Power Electronics, Machines and Drives (PEMD 2010), 2010, pp. 1-6.

[9] T.J. Vyncke, R.K. Boel, J. Melkebeek, "A comparison of stator flux linkage estimators for a direct torque controlled PMSM drive", 35th Annual Conference of IEEE Industrial Electronics (IECON '09), 2009, pp. 971 - 978.

[10] Haque, M.E.; Rahman, M.F "Influence of stator resistance variation on direct torque controlled interior permanent magnet synchronous motor drive performance and its compensation". 36th IEEE Industry Applications Conference, 2001, vol.: 4 , pp. $2563-2569$. 